University of New Hampshire

University of New Hampshire Scholars' Repository

3-16-2016

\title{
Extending the institutional repository to include undergraduate research
}

\author{
Eleta Exline \\ University of New Hampshire - Main Campus, eleta.exline@unh.edu
}

Follow this and additional works at: https://scholars.unh.edu/library_pub

Part of the Cataloging and Metadata Commons, and the Scholarly Communication Commons

\section{Recommended Citation}

Exline, Eleta, "Extending the institutional repository to include undergraduate research" (2016). College \& Undergraduate Libraries. 115.

https://scholars.unh.edu/library_pub/115

This Article is brought to you for free and open access by the University Library at University of New Hampshire Scholars' Repository. It has been accepted for inclusion in University Library Scholarship by an authorized administrator of University of New Hampshire Scholars' Repository. For more information, please contact Scholarly.Communication@unh.edu. 


\title{
Extending the institutional repository to include undergraduate research
}

\section{Running title: Extending the IR to include undergraduate research}

Contact:

Eleta Exline, MS LIS

Scholarly Communication Coordinator

University Library

University of New Hampshire

Durham, NH 03824

eleta.exline@unh.edu

\begin{abstract}
While a primary strategy of scholarly communication initiatives has been to encourage faculty participation in institutional repositories (IRs), with some process and workflow customization, IR participation can be successfully extended to undergraduate students, with benefits to both the student and institution. Drawing observations from the University of New Hampshire Library's work collecting undergraduate honors theses and other student research, this paper discusses customization strategies for creating an effective workflow for student self-deposit using an iterative, feedbackbased approach, and the benefits, challenges, and potential concerns of encouraging undergraduate participation in institutional repositories.
\end{abstract}

Keywords: Institutional repositories, undergraduate research, usability, theses, case study

\section{Introduction}

The University of New Hampshire (UNH) Scholarly Communication Office, part of the University Library, launched the UNH Scholars'

Repository in September 2011 (University of New Hampshire 2014). While 
it was always our intention to include undergraduate work in our institutional repository, our central location for collecting and promoting scholarship and creative work by members of the UNH community, the initial thrust of our content recruitment efforts was focused on faculty publications and graduate-level work. Perhaps naively, we considered faculty to be our primary audience and source of content and assumed collecting graduate theses and dissertations would be an easy first project; collecting undergraduate research was of peripheral concern. While attempting to follow this course of action we experienced several setbacks. Unexpectedly, we found stronger campus support and fewer barriers to collecting undergraduate research than faculty and graduate student scholarship. After drawing observations from the library's work collecting undergraduate honors theses, this paper discusses our strategies for creating an effective workflow for student self-deposit, possibilities for expanding this service to undergraduate research other than honors theses, and the benefits and potential concerns of encouraging undergraduate participation in institutional repositories.

\section{Literature Review}

While a typical trajectory for institutional repository content development is to begin with recruiting published faculty scholarship and implementing electronic theses and dissertations (ETDs), many institutions 
collect undergraduate research, and some prioritize this category of scholarship over other types of content. In a 2006 examination of the contents of known American institutional repositories, McDowell (2007) reports that $41.5 \%$ were determined to be student materials, mostly ETDs, with honors theses and other student work making up about $4.5 \%$ of the total. Nykanen (2011), in a limited study of institutions enrolling fewer than 10,000 students, reports a higher figure of $62.7 \%$ student content, suggesting that smaller institutions put more than average emphasis on collecting student scholarship. An earlier study supports this assertion with more specific information on undergraduate work; Markey, et al. (2008) found that in baccalaureate and master's degree granting institutions undergraduate scholarship made up an equal share of repository content as faculty scholarship (27.3\%). In a survey of 35 institutions Pickton and McKnight (2007) found that ETDs were by far the most common materials collected in repositories, but respondents showed broad support for including undergraduate research in addition to graduate and faculty works. When collected, undergraduate honors theses are among the most downloaded repository content (Connell 2011).

In a case study of Trinity University's IR implementation, Nolan and Costanza (2006) discuss their reasons for beginning with the collection of undergraduate honors theses rather than faculty publications. Strategically, they hoped to indirectly increase awareness about scholarly communication 
issues among faculty working closely with student IR participants. Students also more readily perceived the value in increasing exposure of their work to an online audience, especially those students applying to graduate school who could use the repository as a portfolio. More generally, the authors suggest that participation in the repository by undergraduates exposes them to information about alternative publishing and copyright, introducing them to a "larger scholarly world" (92), and could help strengthen institutional ties to students who will eventually become alumni. Nykanen (2011) additionally suggests that prospective students and their parents might use materials in the IR as a means of evaluating the undergraduate research program at a given institution. Davis-Kahl (2012), in an overview of schoalry communication outreach to students, states that students are highly responsive to social justice issues and acutely aware of the high cost of educational resources. They may therefore find the democratizing effects of open access compelling. This engagement with the concepts underlying open access makes students ideal IR contributors and promoters of scholarly communication initiatives on campus.

Among repository managers, tempering enthusiasm for collecting undergraduate scholarship are concerns about its quality when compared to the work of more mature scholars, a difference that might be more pronounced and potentially confusing when faculty and student works are integrated in repository searches. Some institutions create multiple 
repositories in order to segregate undergraduate work from faculty and graduate-level work to avoid anticipated problems with mixing content (Pickton and McKnight 2007). While honors theses are seen as ideal undergraduate content to include in IRs because they are vetted by faculty, readily accessible, and have few copyright issues, some institutions do not allow student-self deposits because of concerns about the quality and consistency of metadata (Owen 2011). Faculty express additional concerns about compromising the student's future publishing opportunities by prepublishing the work online, and may actively discourage students from participating (Nolan and Costanza 2006). This worry is especially acute when the work involves student-faculty collaboration, where faculty's own publication opportunities may be jeopardized and confidential lab protocols may be exposed (Stern 2014). Across institutions a wide range of policies are applied to the collection of undergraduate work. The most liberal policies allow the deposit of any student work fitting the broad category of scholarship. In an attempt to mitigate concerns about quality and prepublication, the most conservative policies permit collecting only peerreviewed articles or those co-authored by faculty (Pickton and McKnight 2007).

Collecting undergraduate research in institutional repositories is a common practice with potential benefits for both students and institutions. The practice can be used as a strategic means of heightening awareness of 
repositories and drawing attention to scholarly communication initiatives and concepts. The perception that undergraduate scholarship and student produced metadata may have quality issues is a primary concern of repository managers. This paper adds to the case study literature an example of an undergraduate research repository initiative focused on student self-deposit.

\section{Background}

Outreach to faculty and establishing a workflow for depositing previously published journal articles, including researching publisher open access policies, consumed much of our available staff resources in the early days of the UNH Scholars' Repository. Without an open access mandate in place and relatively low baseline awareness of scholarly communication issues among our faculty, recruiting faculty work has been a challenging process and intensive learning experience for Scholarly Communication staff.

As with recruiting faculty scholarship, our initial attempts to collect graduate student research met with unexpected challenges. Our first goal involving student work was to transition from a paper process to ETDs. We approached this project early in the life of the repository because we had heard anecdotally from other repository managers that implementing ETDs was the fastest way to collect a significant quantity of high-quality material 
while simultaneously establishing the repository as a valued resource for the university community. Switching to electronic deposit would ease some of the financial burden on students expected to pay for printing and binding multiple copies, while simultaneously allowing us to provide better, more open access to these materials. The problematic aspect of this project lay somewhat outside the library's sphere of influence - a multi-year timeline was ultimately set by our Graduate School and would require campus-wide policy changes before an electronic process could be approved and implemented. We continue to work toward this goal, although now more for the benefits an electronic submission process would bring to our campus community than as a strategy for short-term repository success.

When we began working with undergraduate materials, a project initiated from outside the library, the process was unexpectedly straightforward and relatively easy in comparison with our efforts collecting faculty and graduate student work. With a ready stream of content flowing from our University Honors Program, the bulk of the work of this project has been in the customization of the repository to fit our needs for describing and accessing that content, and identifying and eradicating barriers to voluntary self-deposit by students.

\section{University Honors Program}


The University of New Hampshire Honors Program, in which approximately 900 students are enrolled each year, provides opportunities for students to participate in a diverse, inclusive community focused on academic excellence and scholarly inquiry (University of New Hampshire 2014a). A requirement of graduating from the University Honors Program is the completion of a four to eight credit Senior Honors Thesis, an independent project in the student's major field undertaken with a faculty advisor. In addition to producing a thesis project, students also present their research at one of many venues in the annual, weeklong Undergraduate Research Conference (University of New Hampshire 2014b) and they may submit articles to the Inquiry Journal, the university's multidisciplinary undergraduate research journal (University of New Hampshire 2014c).

\section{Honors Theses Project - Year 1}

In April 2012 the Assistant Director of the University Honors Program contacted the library about archiving electronic versions of senior honors theses. The desired outcomes of building an electronic collection of honors theses were to provide an easy way for students to review projects submitted by previous students and to simplify the archiving process by eliminating the requirement that students print and bind theses for inclusion in the University Archives. Once the idea was proposed, it took very little 
discussion among the University Archives, Honors Program, and Scholarly Communication staff to agree that the Scholars' Repository should be the future home for these projects. Since the Honors Program staff were interested in implementing a new procedure right away, a mere few weeks prior to graduation, we quickly devised a plan that would allow students to submit spring projects to the University Honors Program electronically, while giving us time to set-up the necessary infrastructure in the Scholars' Repository. In this first year Honors Program staff collected PDF documents and basic metadata directly from students, along with signed paper permissions forms that were provided by the University Archivist. Students were permitted to opt-out of the process. After graduation in May these materials were passed to the Scholarly Communication Office in a single batch of about 60 documents.

Working with BEPress, the vendor for our Digital Commons repository platform, the Scholarly Communication Office set up a new collection in the Scholars' Repository using a standard Digital Commons thesis template with fields for title, authors, date, advisors, subjects, keywords, and abstract. The most challenging aspect of depositing this first batch of honors theses into the Scholars' Repository was that, since there is no generalized template at $\mathrm{UNH}$ for formatting undergraduate theses across colleges, schools, and departments - some departments have templates or guidelines and some do not - basic descriptive information 
was not always available on the title page or within the text of individual theses. In particular, thesis project advisors were not always listed. In some cases, multiple names were listed, but it was not clear if those were advisors, program directors, or co-authors (a few departments allow multistudent projects). Some of this information, such as an unspecified name, could be gathered with limited research; however, it was not possible to fill in all fields for every thesis. Subjects, which were selected from a controlled taxonomy maintained by BEPress, were also difficult to assign, as some theses focused on very narrowly defined academic disciplines or topics. The Scholarly Communication staff working on these records were not catalogers trained in subject assignment, and they had only general, high-level knowledge of the subject areas.

Once the first batch of honors theses was deposited, Honors Program staff reviewed the records. We added or reordered metadata fields based on brief email exchanges between Honors Program staff and Scholarly Communication Office staff about how the collection might be used, which access points were most important, and what would make most sense to the student audience we hoped to serve. In particular, Honors Program staff wanted students to be able to search by college or school, department, and program. Custom fields for these data types were added, along with college/school and department lists for controlled data entry. The "Program" field was left uncontrolled because of the great number of 
interdisciplinary and unique program combinations possible - a project undertaken in both the English and Kinesiology Departments comes to mind as a relevant example. The added custom fields could not be indexed for searching because they were not part of the repository data structure since Digital Commons repositories are searchable across institutions, the underlying data structure must be standardized to support interoperability. As a workaround to the indexing issue, we also added college/school, department, and program information in the "key words" field for searching. As another access point we planned to create automated collections, which essentially look and behave like other collections, but are built using saved search criteria. In this case we would create an automated collection for each department, then pull content into those collections based on the contents of the department field.

\section{Honors Thesis Project - Year 2}

Prepared with more information about the content and structure of honors theses and the functionality of our chosen platform, we devised an informal strategy for implementing student self-deposit for the next wave of honors theses to be completed in fall 2012. Each student participating in this voluntary process would be required to consent to an online submission agreement allowing us to post the thesis online, enter basic metadata into a submission form, and upload the thesis document into the 
repository. We revised the vendor-provided legal boilerplate in the submission agreement to simpler, student-friendly language, and eliminated any unnecessary provisions. We also reviewed and revised the submission form fields and completion instructions, attempting to either correct or eliminate anything confusing. Since the fall graduation date is much less popular than spring, only a small number of students would be submitting theses at that time, giving us an ideal opportunity to pilot the self-archiving process with a small group. The Honors Program Assistant Director, the primary contact for students in the program, drafted a letter to graduating seniors telling them about the new process and asking for their feedback to help us refine it. Although students gave few comments on the process, some reported back to the Assistant Director that the requirement to create an account prior to depositing was inconvenient.

Once fall 2012 honors thesis submissions came in, library staff reviewed the records and noted "errors" in the metadata before correcting and publishing the submissions. We assumed that the occurrence of errors showed a lack of clarity in the submission process rather that any fault of the students submitting the forms. The only fields in which students consistently had trouble were those for the "date" and "advisor," and in both cases this was clearly due to a lack of instructions. In both cases the students typically provided more information than was needed. For "date," which was labeled "Date of Award," we wanted only the semester of 
graduation (Fall 2012), but would instead get a specific date - whether these were the anticipated day of graduation, day the thesis was completed or approved, or the day graduation forms were submitted, we could not be sure. For "advisor" we wanted a name, but students would often include honorifics and degree designations. Since issues with these two fields could be easily resolved by deleting the extra information, we delayed making any changes to the submission form until after the spring 2013 submissions so that we could gather more information via our library website usability testing program in the fall of 2013.

\section{Usability Testing}

Several times a year the library conducts a session of usability tests for sections of the UNH library's website. Our Web Developer, who produces a written report of findings for the library and suggests remedies for any problems identified, manages this program. In each session, two or three volunteer participants, prompted by a script, individually work through a series of tasks related to finding information on the site, using a service, or locating library collection materials. The participants are asked to "think out loud" while working through the tasks and may be asked to elaborate on their thoughts and actions throughout the test - an adaptation of Steve Krug's suggested methods. The session is broadcast live to a group of 
library staff observers, and the screen and audio of the test are recorded for later analysis.

By including tasks using the Honors Theses collection in a usability test session we had hoped to gain more information about how students perceived the submission process and form, but instead we identified more significant problems that could interfere with use of or participation in the repository. Starting from the library's website, participants were asked to complete two honors thesis related tasks: 1) to find a particular thesis in the collection and 2) to deposit a document in the collection. Since all participants had difficulty finding the Scholars' Repository from the library website, they were eventually asked to navigate directly to the site and begin from there. From the repository home page participants had difficultly locating the Honors Theses collection to find a previously deposited work, and they consistently tried to deposit their documents in the faculty research collections organized by department, rather than seek out the student research section in which the Honors Theses collection resided. Once the participants located a place to submit a document, the wrong place in each case, they were prompted to first create an account. Since creating an account is a multi-step process requiring one to access email to confirm the account, participants were reluctant to complete the process for a one-time transaction. The repository portion of the test ended 
at this point without any of the participants getting far enough along to interact with the submission form.

To those who observed the usability test it was clear that our approach to promoting repository information on the library website needed to be rethought, and that within the Scholars' Repository site, access to the Honors Theses collection needed to be more prominent. The reason that this findability issue had not previously been perceived as a major problem was because students completing an honors thesis were given a direct link to the repository site by Honors Program staff. While effective in the short term, we could not rely on direct referrals to the site as the only means of access if we wanted students to use it to find sample theses and to independently submit work. The usability testing report recommended creating task-oriented pages on the library website, such as a "Find a thesis or dissertation" page with specific instructions on accessing this content in various locations and a "Submit your thesis" page linking to the correct section of the Scholars' Repository. The report also suggested adding navigational clues on the Scholars' Repository site and rethinking the account creation process, echoing feedback from students who made deposits in the prior semester (Wolff 2013).

\section{Honors Theses Project - Year 3}


In preparation for the third year of the Honors Theses project, and the second year of self-deposits by students, we made several changes to the Scholars' Repository site and the submission process. These changes responded to results of usability testing, the nature of the "errors" in the student entered metadata, and feedback from Honors Program students and staff. Because of the timing of usability testing, the changes were made after the small batch of fall 2013 deposits. The Honors Theses collection is now prominently linked from the Scholars' Repository home page, which should make it easier to find once one is already on the site. Changes to the library website to make the Scholars' Repository links more prominent are being completed as part of a separate process involving a team of library staff, and links have been added from the Honors Program website in a section outlining the steps for completing an honors thesis project. We have eliminated the requirement to create an account when depositing a document. We considered requiring an email address for the submitting author, but we could not make this change without also requiring email addresses for co-authors; we decided against it as another unnecessary barrier to completing the submission form. While the lack of an account or email address in the system would limit the ability for students to revise submissions or for us to contact them with questions, we considered this a fair trade for making the process less burdensome. Few students in the first two years of the project had ever made a revision to a 
submission, and they could contact the library or Honors Program if they

wished to do so. It is also possible for us to look up the email addresses of students in an online directory if we truly need to be in touch about a submission. We have changed the "date" field so that only the semester and year can be entered, and we have added instructions to the "advisor" field asking that only first and last names be entered, not titles or degrees.

\section{Participation Rates}

While statistics on the number of deposits made each academic session are available through our repository reporting function, the total number of participants graduating from the Honors Program is available only by calendar year. Table 1 shows the number of honors theses deposited per academic session, the percentage that number is of all honors projects for the corresponding calendar year, and whether deposits were mediated by Honors Program staff or self-deposited by students. The highest participation rate in this initiative was in 2012 , when all deposits were mediated in the spring and students were encouraged to participate in a pilot in the fall. In the following year, when students completed all deposits on their own, the participation rate dropped to $39.7 \%$. Prior to the spring 2014 session the deposit form was revised extensively and the requirement to create an account prior to deposit was removed. The deposit rate increased slightly to $41.6 \%$. Clearly participation is higher 
when deposits are mediated directly by staff, but revising the process in response to usability testing, review of metadata "errors," and student feedback may have contributed to the slight increase in deposits from 2013 to 2014. We did not track the number of reminders to deposit sent to the students throughout each academic session - doing so in the coming year may give us additional insights into the factors influencing participation rates.

Table 1. Number of Honors Theses deposited per academic session and participation rate by year.

\begin{tabular}{|c|c|c|c|c|}
\hline \multirow{2}{*}{2012} & Session & Deposits & Participation & Type \\
\hline & Spring & 60 & & Mediated \\
\cline { 2 - 3 } & Summer & 2 & \multirow{2}{*}{$58.8 \%$} & \\
\cline { 2 - 3 } & Fall & 18 & & \\
\hline \multirow{2}{*}{2013} & Spring & 53 & \multicolumn{2}{|c}{} \\
\cline { 2 - 3 } & Summer & 1 & \multirow{2}{*}{$39.7 \%$} & \multirow{2}{*}{ Self-deposit } \\
\cline { 2 - 3 } & Fall & 8 & \multicolumn{2}{|c}{} \\
\hline 2014 & Spring & 42 & $41.6 \%$ & \\
\hline
\end{tabular}

Overall our strategy for customizing the Scholars' Repository for student work has employed making incremental changes based on feedback and our observations of user behaviors. Because both the repository and self-deposit were new to us, as was collecting electronic 
versions of undergraduate work, this responsive process seemed more rational than trying to predesign an ideal procedure based on what we imagined students would do and how they might use the collection. An informal and iterative approach to the customization of repository collections works for us for at least a few reasons: 1) we were working within the framework and with the templates of a submission process that was already established within our repository platform, with customization, not whole-cloth invention of a process, as our goal; 2) our library is accustomed to working with usability testing, analysis of website use statistics, and similar methods for observing user behavior to guide website changes, so this was in keeping with our organizational culture; and 3) the Honors Theses project competed for time with other repository initiatives to collect faculty and graduate student work - with limited resources we could not spare time for anything less pragmatic. We fully expect to discover additional refinements that need to be made to the thesis submission process, now that we have eliminated the most obvious barriers to participation. While we run the risk of metadata inconsistencies over time if we continue to change our procedures in response to new feedback, this may be true of any collecting practice that spans a longer timeframe, and it is not unique to repository collections. Our hope is that these changes will lead to higher participation rates in the fourth and subsequent years of 
Honors Theses self-deposits than the approximately $40 \%$ that we have experienced so far, and we will report our findings if this is the case.

\section{The Inquiry Journal}

An unexpected benefit of working closely with the Honors Program is that is has given us the opportunity to make other connections to those within the university involved in promoting other forms of undergraduate research. Within a few months of collecting our first honors theses we were contacted by the managing editor of Inquiry Journal, who was referred by Honors Program staff, about archiving past issues. The Inquiry Journal, which is published each spring, had just undergone a website redesign and the new version of the site was about to be launched, but staff had not yet resolved how the old content would be archived and accessed. Scholarly Communication and Inquiry Journal staff met to discuss the journal's content, and options for configuring an archive of back issues in the Scholars' Repository that could be reciprocally linked with the current issue. We received the content of eight years' worth of back issues and structured them for display to reflect the original format of the journal as much as possible. While archiving a journal is not the same as hosting it, and does not allow us the opportunity to work directly with the Inquiry Journal staff and students on the editorial process or intellectual property rights issues, it does give library Scholarly Communication staff welcome additional 
exposure to how student research is conducted on campus, information on the depth and breadth of the undergraduate research program, and helps us establish contacts with the staff involved. We are also able to provide a needed service in archiving web content, which can be considered ephemeral if not actively curated. Our hope is that before long there will be an opportunity for us to host a student journal in the repository, and that archiving the Inquiry Journal will have partially prepared us for the challenge.

\section{Undergraduate Research Conference}

In an effort to expand our experience with undergraduate research and develop a richer collection from a broader selection of students, the Scholarly Communication librarian and University Archivist recently attended several sessions of the extensive UNH Undergraduate Research Conference (URC). About 1,100 to 1,300 undergraduates participate in the URC in a series of events in multiple venues spread across our campuses in Durham and Manchester. While we were only able to attend a few of the scheduled events, many of which occur simultaneously, we passed out flyers on how to deposit posters and other research to students in the two largest poster presentation sessions. These activities took place just a few days prior to the submission of this paper and after a follow-up email to about 500 poster presenters, we have received 18 deposits to our new 
Student Research Projects collection in the Scholars' Repository, which is similarly configured to the Honors Theses collection. It is already clear that without the direct encouragement to deposit research from familiar program staff or faculty, which we have benefited from in collecting honors theses, URC student participation in the repository will be low.

\section{Benefits and challenges of collecting student research}

Our primary motivations for the Honors Theses project were to eliminate collecting paper copies of theses and to give students searchable access to past projects as examples. However, the potential benefits are much broader. In the UNH library we are just beginning to see how the Scholars' Repository can help us make and sustain connections across the university, contribute more broadly to the teaching and research mission, and support students in their aspirations as undergraduate scholars and beyond graduation. Whether the author is a faculty member, graduate student, or undergraduate, the interaction that happens when a work is deposited in a library hosted repository affords librarians the opportunity to discuss open access publishing, the management of intellectual property, and the assessment of research impacts - while we have yet to fully develop this potential at $\mathrm{UNH}$, it is an endeavor that deserves more of our time and attention. Whether or not UNH undergraduates intend to continue their formal education at the graduate level, exposure to scholarly 
communication issues will contribute to preparing students for their life-long roles as content creators, intellectual property owners, and citizen scholars.

As other intuitions implementing similar projects have found, the repository provides students ongoing access to projects after graduation and helps foster an enduring connection to their undergraduate institution. In the absence of a student portfolio system, the continuing access to research projects provided by the repository could be particularly useful to students applying to graduate programs. At UNH, placing student work in the repository allows us to expose our extensive undergraduate research program to a greater audience, enhancing the institution's reputation for supporting students in the pursuit of a deep research experience and potentially giving us a competitive edge in recruitment. Student research has constantly been the most downloaded content in our repository.

During the implementation of the Honors Theses project we received a few questions from students and faculty advisors who had concerns about participating in the program. These concerns were about the ability to publish from previously deposited work, the potential for plagiarism, and exposure of confidential or proprietary research when students worked on ongoing faculty projects. When students or faculty collaborators have concerns about keeping publishable or ongoing research confidential, we have offered to embargo projects for a period of time or post only an abstract as a record of the student's research involvement - the abstract 
only option has been used a few times, but the embargo option has not. As for the plagiarism question, we assure faculty that including student research in the repository could make it less susceptible to plagiarism by exposing it to plagiarism detection software commonly used to screen student work in higher education settings. It also establishes the authorship and date of a project, should a plagiarism incident arise. A potential, though as yet unspoken, concern is that exposing the relatively immature research efforts of an undergraduate author could compromise the reputation of that author as more mature scholar in the future. While we could and would withdraw a submission at the author's request, we could not guarantee that other copies had not been posted elsewhere online. While there is not an entirely satisfactory solution to this potential concern, a possible solution would be to limit access of student work to the UNH campuses and alumni. Most concerns about depositing student work in the repository are easily resolved but point to negative perceptions of the practice that need to be addressed more broadly and fully if we are to eventually pass the $50 \%$ mark for student researcher participation in selfdeposit.

\section{Future plans}

In the coming year we will continue to monitor submissions to both our Honors Theses and Student Research Projects collections, and we may 
follow-up with additional website usability tests to identify any missed or new barriers to student participation in self-deposit of research. We will vary our approach to the URC by attempting to become involved in the early stages of the organization of the event, which may afford us additional opportunities to discuss the archiving of student work with those who have more direct contact with the student researchers, while broadening our own experience in this area. We may also be able to incorporate information about the repository into program literature and other material submitted to students, as appropriate.

In addition to recruiting more student content for the Scholars' Repository, we would like to explore ways to support students engaged in research projects more directly through library programs and services. One option is providing specialized instruction and help sessions for these students, including information on scholarly communication issues, such as open access publishing and the management of intellectual property. If anything, our experience over the past three years highlights how little direct exposure to students we librarians who are not on the front lines of reference and instruction have, a situation that can be remedied with more effort to engage meaningfully with both student issues and students themselves.

\section{References}


Connell, Tschera Harkness. 2011. "The Use of Institutional Repositories: The Ohio State University Experience." College \& Research Libraries 72 (3): 253-75.

Markey, Karen, Beth St Jean, Young Rieh Soo, Elizabeth Yakel, and Jihyun Kim. 2008. "Institutional Repositories: The Experience of Master's and Baccalaureate Institutions." Portal: Libraries and the Academy 8 (2): 157-73. doi:10.1353/pla.2008.0022.

McDowell, Cat S. 2007. "Evaluating Institutional Repository Deployment in American Academe Since Early 2005: Repositories by the Numbers, Part 2." D-Lib Magazine 13 (9/10). doi:10.1045/september2007mcdowell.

Nolan, Christopher W., and Jane Costanza. 2006. "Promoting and Archiving Student Work through an Institutional Repository: Trinity University, LASR, and the Digital Commons." Serials Review 32 (2): 92-98. doi:10.1080/00987913.2006.10765038.

Nykanen, Melissa. 2011. "Institutional Repositories at Small Institutions in America: Some Current Trends." Journal of Electronic Resources Librarianship 23 (1): 1-19. doi:10.1080/1941126X.2011.551089.

Owen, Terry M. 2011. "Evolution of a Digital Repository: One Institution\&\#039;s Experience." Journal of Electronic Resources Librarianship 23 (2): 142-49. doi:10.1080/1941126X.2011.576959.

Pickton, Margaret, and Cliff McKnight. 2007. "Is There a Role for Research Students in an Institutional Repository? Some Repository Managers' Views." Journal of Librarianship and Information Science 39 (3): 15361. doi:10.1177/0961000607080418.

Stern, David. 2014. "Student Embargoes within Institutional Repositories: Faculty Early Transparency Concerns." Journal of Librarianship and Scholarly Communication 2 (2). doi:http://dx.doi.org/10.7710/21623309.1080.

University of New Hampshire. 2014. "University of New Hampshire Scholars' Repository.” Accessed May 1, 2014. http://scholars.unh.edu/.

- - . 2014a. "University of New Hampshire, Honors Program." Accessed May 1, 2014. http://www.unh.edu/honors-program/. 
- - . 2014b. "Undergraduate Research Conference." Accessed May 1, 2014. http://www.unh.edu/urc/.

- - . 2014c. "Inquiry Journal." http://www.unh.edu/inquiryjournal/.

Wolff, Robert. 2013. "Usability Testing Report" 